\title{
Hubungan Karakteristik Pembudidaya Ikan terhadap Adopsi Inovasi Pakan Alami Ikan di Kecamatan Darmaraja Kabupaten Sumedang
}

[Relationship of the characteristict of fish cultivator groups on the adoption of natural fish feed innovation Darmaraja Subdistrict, Sumedang Regency]

\author{
Nisfi Darwita, Sopiyan Danapraja, Ani Leilani \\ Sekolah Tinggi Perikanan Jurusan Penyuluhan Perikanan \\ Jalan Cikaret Nomor 2, Bogor
}

Diterima: 18 September 2018; Disetujui: 28 November 2018

\begin{abstract}
Abstrak
Penelitian ini bertujuan untuk: (1) mengetahui keeratan hubungan karakteristik pembudidaya terhadap tingkat adopsi inovasi pakan alami ikan (2) mengetahui tingkat adopsi inovasi berdasarkan kelas kelompok. Penelitian dilakukan di Kelompok Mina Mukti dan Kelompok Cipta Rasa Kecamatan Darmaraja Kabupaten Sumedang, pada bulan Februari sampai Mei 2018. Teknik pengumpulan data menggunakan kuesioner, wawancara, dan observasi sedangkan teknik analisis data menggunakan analisis deskriptif. Hasil penelitian menunjukkan bahwa: (1) Karakteristik pembudidaya seperti umur, pendidikan, lama usaha, luas lahan dan pendapatan berhubungan dengan tingkat adopsi inovasi pakan alami ikan; (2) Tingkat adopsi inovasi pada kelompok madya (Mina Mukti) lebih tinggi dibandingkan kelompok pemula (Cipta Rasa).
\end{abstract}

Kata Kunci: karakteristik; adopsi; inovasi; pakan alami

\section{Abstract}

This research aims to: (1) to know closeness of the relationship between the characteristic of the cultivators on the adoption of natural fish feed innovations (2) know the level of innovation adoption in the beginner and middle groups. The study was conducted in Mina Mukti Group and Cipta Rasa Group in Darmaraja Subdistrict, Sumedang Regency, from February to May 2018. Data collection techniques used questionnaires, interviews, and observations while data analysis techniques used descriptive analysis. The results showed that: (1) Characteristics of cultivators such as age, education, length of business, land area and income could influence the adoption of innovation in natural fish feed (2) The rate of adoption of innovation in middle class (Mina Mukti) was higher than the beginner group (Cipta Rasa).

Keywords: characteristic; adoption; innovation; natural fish feed

Penulis korespondensi

Nisfi Darwita | nisfid@gmail.com

\section{PENDAHULUAN}

Kecamatan Darmaraja memi-liki potensi perikanan yang beragam diantaranya potensi Kolam Air Tenang
(KAT) seluas 18,278 $\mathrm{Ha}$ baru termanfaatkan untuk pembenihan $2,060 \mathrm{Ha}$ dan pembesaran seluas 16,219 $\mathrm{Ha}$, Kolam Air Deras (KAD) seluas $5 \mathrm{Ha}$ 
belum dimanfaatkan, Mina Padi (MPD) seluas $775 \mathrm{Ha}$ baru diman-faatkan seluas 0,1 Ha dan Perairan Umum (PU) sepanjang 21,7 km dan waduk Jatigede seluas $4.420,15 \mathrm{Ha}$ belum dimanfaatkan secara optimal (Rosiah 2017).

Berdasarkan fakta diatas, maka perlunya pemanfaatan potensi yang optimal. Salah satu upaya yang dilakukan dengan memberikan inovasi kepada pembudidaya sehingga dapat meningkatkan hasil produksi yang ber-ujung pada kesejahteraan pembudi-daya itu sendiri.

Penelitian ini bertujuan untuk (1) mengetahui keeratan hubungan karakteristik pembudidaya terhadap tingkat adopsi inovasi pakan alami ikan (2) mengetahui tingkat adopsi inovasi berdasarkan kelas kelompok.

\section{BAHAN DAN METODE}

Penelitian telah dilaksanakan di Desa Cieunteung dan Neglasari, Kecamatan Darmaraja Kabupaten Sumedang Provinsi Jawa Barat, pada bulan Februari sampai dengan April 2018. Populasi dari penelitian adalah ang-gota Kelompok Pembudidaya Ikan di Kecamatan Darmaraja. Teknik sampel yang digunakan adalah sensus dengan jumlah sampel yang diambil adalah 30 RTP dari dua kelompok pembudidaya ikan Nila di Kecamatan Darmaraja.
Metode pengumpulan data pada adalah wawancara dan alat pengumpulan data dengan menggunakan kuisioner dengan jenis data yaitu data primer dan data sekunder. Setelah semua data terkumpul, dilakukan pengolahan data dengan menggunakan metode deskriptif yaitu, statistik yang digunakan untuk menganalisis data dengan cara mendiskripsikan atau menggambarkan data yang telah terkumpul sebagaimana adanya tanpa bermaksud membuat kesimpulan yang berlaku untuk umum atau generalisasi (Sugi-yono 2000).

\section{HASIL DAN PEMBAHASAN}

Hasil

Hasil penelitian yang diperoleh berupa data karakteristik pembudidaya ikan, yang terdiri atas parameter: usia, tingkat pendidikan, lama usaha, luas lahan, pendapatan bulanan, motivasi dan tingkat partisipasi dari kelompok pembudidaya (pokdakkan) Mina Muk-ti dan Cipta Rasa, dapat dilihat pada Tabel 1. Sedangkan hasil penelitian tentang tingkat adopsi demcar budi-daya maggot, dempond pembenihan i-kan nila, dan demcar budidaya Daph-nia sp. dari pokdakkan Mina Mukti terlihat pada Tabel 2, dan pokdakkan Cipta rasa terlihat pada Tabel 3. 
Tabel 1. Karaktersitik pembudidaya ikan

\begin{tabular}{|c|c|c|c|c|c|c|c|}
\hline \multirow{3}{*}{$\begin{array}{l}\text { Karakteristik } \\
\text { Pembudidaya }\end{array}$} & \multirow{3}{*}{ Kategori } & \multicolumn{3}{|c|}{ Minamukti } & \multicolumn{3}{|c|}{ Cipta Rasa } \\
\hline & & \multicolumn{2}{|c|}{ Jumlah } & \multirow{2}{*}{ Rata-Rata } & \multicolumn{2}{|c|}{ Jumlah } & \multirow{2}{*}{ Rata-Rata } \\
\hline & & $\mathbf{N}$ & $\%$ & & $\mathbf{N}$ & $\%$ & \\
\hline \multirow{3}{*}{$\begin{array}{l}\text { Usia (Tahun) } \\
\text { (UU No.13 tahun 2003) }\end{array}$} & Produktif (15-63) & 11 & 100 & 39 tahun & 20 & 100 & 49 tahun \\
\hline & Tldak Produktif $(<15)$ & 0 & 0 & & 0 & 0 & \\
\hline & Kurang Produktif (>64) & 0 & 0 & & 0 & 0 & \\
\hline \multirow{3}{*}{$\begin{array}{l}\text { Tingkat Pendidikan } \\
\text { (Kemendiknas RI, } \\
\text { 2003) }\end{array}$} & Dasar (<SMP) & 8 & 73 & & 15 & 75 & \\
\hline & Menengah (SMP-SMA) & 2 & 18 & & 5 & 25 & \\
\hline & $\begin{array}{l}\text { Sedang (Pendidikan } \\
\text { Tinggi) }\end{array}$ & 1 & 9 & & 0 & 0 & \\
\hline \multirow{3}{*}{$\begin{array}{l}\text { Lama Usaha } \\
\text { (Manyamsari dan } \\
\text { Mujiburrahmad 2014) }\end{array}$} & Baru (<10 tahun) & 10 & 91 & 5.2 tahun & 20 & 100 & 3 tahun \\
\hline & Sedang (10-20 tahun) & 1 & 9 & & 0 & 0 & \\
\hline & Lama ( $>20$ tahun) & 0 & 0 & & 0 & 0 & \\
\hline \multirow{3}{*}{$\begin{array}{l}\text { Luas Lahan } \\
\text { (Manyamsari dan } \\
\text { Mujiburrahmad 2014) }\end{array}$} & Sempit $\left(<1000 m^{2}\right)$ & 7 & 64 & $899.5 \mathrm{~m}^{2}$ & 20 & 100 & $214 \mathrm{~m}^{2}$ \\
\hline & Sedang $\left(1000-2000 \mathrm{~m}^{2}\right)$ & 2 & 18 & & 0 & 0 & \\
\hline & Luas $\left(>2000 \mathrm{~m}^{2}\right)$ & 2 & 18 & & & & \\
\hline \multirow{3}{*}{$\begin{array}{l}\text { Pendapatan/Bulan } \\
\text { (UMK=2.678.028) }\end{array}$} & Kecil (<UMK) & 10 & 90 & Rp.1,322,727 & 20 & 100 & Rp. 752,500 \\
\hline & Sedang (=UMK) & 0 & 0 & & 0 & 0 & \\
\hline & Tinggi (>UMK) & 1 & 10 & & & & \\
\hline \multirow{3}{*}{$\begin{array}{l}\text { Motivasi } \\
\text { (Manurung 2009) }\end{array}$} & Rendah (1-7) & 0 & 0 & Sedang & 10 & 50 & Rendah \\
\hline & Sedang (8-16) & 7 & 64 & & 5 & 25 & \\
\hline & Tinggi (17-25) & 4 & 36 & & 5 & 25 & \\
\hline \multirow{3}{*}{$\begin{array}{l}\text { Partisipasi } \\
\text { (Manurung 2009) }\end{array}$} & Rendah (1-7) & 5 & 46 & Rendah & 9 & 45 & Rendah \\
\hline & Sedang (8-16) & 4 & 36 & & 7 & 35 & \\
\hline & Tinggi (17-25) & 2 & 18 & & 4 & 20 & \\
\hline
\end{tabular}

Tabel 2. Adopsi inovasi Pokdakan Mina Mukti

\begin{tabular}{llllll}
\hline \multirow{2}{*}{\multicolumn{1}{c}{ Program Penyuluhan }} & \multicolumn{5}{c}{ Tingkat Adopsi (Orang) } \\
\cline { 2 - 6 } & Sadar & Minat & Menilai & Mencoba & Menerapkan \\
\hline Demcar Budidaya Maggot & 10 & 6 & 4 & 3 & 2 \\
Dempond Pembenihan Ikan Nila & 11 & 7 & 5 & 3 & 3 \\
Demcar Budidaya Daphnia & 10 & 8 & 6 & 2 & 2 \\
\hline
\end{tabular}

Sumber: Data primer setelah diolah (2018)

\section{Pembahasan}

Karateristik Pembudidaya

Umur pembudidaya, kelompok

Mina Mukti dan Cipta Rasa 100\% me- nunjukkan umur produktif yaitu ber-kisar antara 15-64 tahun. Semakin mu-da umur pembudidaya, maka akan semakin semangat untuk mengetahui hal 
Tabel 3. Adopsi inovasi Pokdakan Cipta Rasa

\begin{tabular}{llllll}
\hline \multirow{2}{*}{\multicolumn{1}{c}{ Program Penyuluhan }} & \multicolumn{5}{c}{ Tingkat Adopsi (Orang) } \\
\cline { 2 - 6 } & Sadar & Minat & Menilai & Mencoba & Menerapkan \\
\hline Demcar Budidaya Maggot & 20 & 6 & 4 & 2 & 1 \\
Dempond Pembenihan Ikan Nila & 10 & 5 & 3 & 3 & 1 \\
Demcar Budidaya Daphnia & 11 & 5 & 2 & 2 & 1 \\
\hline
\end{tabular}

Sumber: Data primer setelah diolah (2018)

baru. Bertolak belakang dengan pendapat Lubis (2000) dalam Amala et al. (2015) yang menyatakan bahwa semakin muda pembudidaya maka lebih cepat melakukan adopsi inovasi

Tingkat pendidikan, kelompok Mina Mukti 73\% pembudidaya berpendidikan dasar dan kelompok Cipta Rasa $75 \%$ berpendidikan dasar. Pendidikan merupakan sarana belajar dimana selanjutnya akan menanamkan sikap pengertian yang menguntungkan menuju pembangunan praktik perika-nan yang lebih modern. Kedua ke-lompok menunjukkan pendidikan ren-dah sehingga proses adopsi inovasi berjalan lambat. Hal ini sesuai dengan pendapat Lubis (2000) dalam Amala et al. (2015) yang mengungkapkan bahwa mereka yang berpendidikan tinggi adalah yang relatif lebih cepat dalam melaksanakan adopsi, begitu pula sebaliknya mereka yang berpen-didikan rendah, agak sulit melaksana-kan adopsi inovasi dengan cepat.

Lama usaha, kelompok Mina Mukti 91\% dan kelompok Cipta Rasa 100\% kategori baru atau $<10$ tahun.
Sedangkan rata-rata lama usaha pada kelompok Mina Mukti 5,4 tahun dan kelompok Cipta Rasa 3 tahun. Usaha pada kelompok Mina Mukti bersifat komersil dan berkelanjutan dan telah mengikuti sebagian anjuran dari penyuluh perikanan, sedangkan usaha pada kelompok Cipta Rasa hanya mengikuti apa yang telah mereka lihat dari sesama pembudidaya ikan Nila, yang dianggap sesuai dengan teknik budidaya ikan Nila yang dianjurkan.

Fakta diatas sesuai dengan pernyataan Soekartawi (1994) dalam Amala et al. (2015), yang menyatakan bahwa faktor pengalaman mempunyai hubungan positif dengan kecepatan adopsi inovasi. pembudidaya yang berpengalaman lebih cepat mengadopsi teknologi dibandingkan dengan pembudidaya yang belum atau kurang berpengalaman. Pembudidaya yang sudah lama melakukan usahanya akan lebih mudah menerapkan inovasi daripada pembudidaya pemula.

Luas Iahan, kelompok Mina Mukti 64\% dan kelompok Cipta Rasa 100\% dalam kategori sempit atau ku-rang dari 
$1000 \mathrm{~m}^{2}$. Rata-rata luas la-han kelompok Mina Mukti 899,4 $\mathrm{m}^{2}$ dan kelompok Cipta Rasa $214 \mathrm{~m}^{2}$. Lu-as lahan menentukan pembudidaya un-tuk dapat mengambil keputusan dalam upaya menerapkan suatu unsur ino-vasi. Ukuran lahan usaha berhubungan positif dengan adopsi. Kelompok Mina Mukti lebih cepat dalam mengadopsi inovasi dibandingkan dengan kelom-pok Cipta Rasa. Hal ini sesuai dengan pernyataan Soekartawi (1994) dalam Amala et al. (2015) yang menyatakan bahwa pembudidaya yang mempunyai lahan yang luas akan lebih mudah me-nerapkan anjuran penyuluhan demi-kian pula halnya dengan penerapan a-dopsi inovasi daripada yang memiliki lahan sempit. Hal ini dikarenakan ke-efisienan dalam penggunaan sarana produksi.

Pendapatan pembudidaya, pada kelompok Mina Mukti 91\% dan kelompok Cipta Rasa 100\% dalam kategori kecil atau kurang dari UMK daerah yaitu sebesar $R p$ 2.678.028,99,Pendapatan rata-rata pembudidaya kelompok Mina Mukti sebesar Rp 1.322.727,- dan pada kelompok Cipta Rasa Rp 752.500,-

Tingkat partisipasi, kelompok Cipta Rasa dan Mina Mukti berada dalam kategori rendah dengan pre-sentase $46 \%$ dan $45 \%$. Pendidikan pa-da kedua kelompok sebagian besar berpendidikan dasar sehingga pada ke-giatan penyuluhan pembudidaya takut untuk bertanya, berdiskusi maupun menyanggah informasi yang disampaikan penyuluh.

Menurut Sari (2010) dalam Amala et al. (2015) dinyatakan bahwa tingkat partisipasi memungkinkan perubahanperubahan yang lebih besar dalam cara berfikir pembudidaya. Perubahan da-lam pemikiran dan tindakan akan lebih sedikit terjadi dan perubahan-peru-bahan ini tidak akan bertahan lama jika pembudidaya menuruti saran-sa-ran dari penyuluh perikanan. Pembu-didaya yang lebih sering mengikuti kegiatan-kegiatan yang berhubungan dengan usaha perikanan akan menda-patkan informasi dan pengetahuan yang lebih banyak sehingga semakin banyak partisipasi pembudidaya maka akan semakin tinggi tingkat adopsi pembudidaya.

Tingkat motivasi, kelompok Mi-na Mukti berada pada kategori sedang dengan jumlah tujuh orang atau $64 \%$ sedangkan kelompok Mina Mukti berada pada kategori rendah dengan jumlah 10 orang atau 50\%. Ketua ke-lompok Cipta Rasa memiliki peran da-lam mendorong anggotanya untuk mengikuti penyuluhan, kesadaran ma-sih rendah.

Tingkat adopsi inovasi pada Pokdakan Mina Mukti lebih tinggi dibandingkan dengan Pokdakan Cipta Rasa. Adapun faktor yang mempengaruhi tingkat adopsi sebagai berikut: 


\section{Skala usaha}

Usaha yang dijalankan pada kelompok Mina Mukti bersifat komersial dan berkelanjutan sedangkan kelom-pok Cipta Rasa usaha bersifat sam-pingan dan masih dalam skala kecil. Menurut Indrianingsih (2016), yang menyatakan bahwa semakin kecil ska-la usaha pembudidaya, maka semakin takut dengan resiko kerugian, Ber-dasarkan kondisi relatif lebih kecilnya skala usaha kelompok pembudidaya Cipta Rasa, membuat tingkat adopsi teknologi yang disampaikan pada le-bih rendah.

\section{Kebiasaan}

Usaha kelompok Mina Mukti te-lah secara turun temurun dilakukan berdasarkan kebiasan sosial budaya setempat, sedangkan pada kelompok Cipta Rasa hanya melihat kebiasaan dari pembudidaya lain yang telah ber-hasil melakukan usaha sesuai dengan budaya setempat. Hasil penelitian In-drianingsih (2016), mengungkapkan bahwa mengubah kebiasaan bukan merupakan pekerjaan yang mudah, apalagi jika berisiko terlalu besar, ter-kait dengan masalah sosial budaya.

\section{Karakteristik pembudidaya}

Karakteristik pembudidaya mempengaruhi adopsi dan inovasi pro-gramprogram penyuluhan. Adapun karaktersitik yang mempengaruhi adalah tingkat pendapatan yang rendah. Kelompok Cipta Rasa memiliki rara-rata pendapatan yang rendah sedang-kan kelompok Mina Mukti memiliki rata-rata sedang, sehingga dapat dilihat adopsi pada kelompok Mina Mukti le-bih rendah. Sebagaimana yang diung-kapkan Warnaen et al. (2016), bahwa faktorfaktor yang menghambat ino-vasi pada komunitas pembudidaya pa-da karakteristik individu pembudidaya adalah pendapatan yang rendah.

\section{Kemudahan untuk mencoba}

Teknologi akan mudah diterima oleh pembudidaya jika mudah untuk dicoba baik dari segi sarana dan prasarana yang tersedia di sekitar. Pada program penyuluhan yang telah dilakukan kelompok Mina Mukti, maka dempond pembenihan ikan Nila dianggap mudah untuk dicoba karena memiliki tingkat pengadopsi yang sama yaitu berjumlah tiga orang. Warnaen et al. (2016), yang menyatakan bahwa karakteristik inovasi yang mengham-bat inovasi petani adalah tingkat ke-rumitan, keunggulan relatif, nilai eko-nomis, tingkat kemudahan untuk dico-ba, bantuan politik.

\section{SIMPULAN}

Berdasarkan pembahasan hasil pe-nelitian yang telah dilakukan, dapat di-simpulkan sebagai berikut : 
1. Karakteristik pembudidaya seperti umur, pendidikan, luas lahan, la-ma usaha, pendapatan, tingkat motivasi dan tingkat partisipasi mempengaruhi kecepatan adopsi inovasi.

2. Kelompok Mina Mukti (Madya) lebih cepat mengadopsi diban-dingkan Kelompok Pembudidaya Cipta Rasa (Pemula).

\section{PERSANTUNAN}

Ucapan terimakasih disampai-kan kepada Ketua Jurusan Penyuluhan Perikanan, Sekolah Tinggi Perikanan, yang telah memberikan kesempatan melakukan kegiatan penelitian bersamaan dengan kegiatan Praktik Akhir Taruna tingkat Utama/IV Jurusan Penyuluhan Perikanan, Sekolah Tinggi Perikanan; kepada Pimpinan Dinas Perikanan dan Peternakan Kabupaten Sumedang Jawa Barat untuk dukungan data sekunder yang diberikan; Unit Pelaksana Teknis (UPT) Wilayah Situ-raja dan Kepala Desa Cieunteung dan Neglasari, atas fasilitas perijinan melakukan penelitian.

\section{DAFTAR PUSTAKA}

Amala AT, D Chalil, L Sihombing. 2015. Faktor-faktor yang ber-hubungan dengan adopsi petani terhadap sistem pertanian padi organik. Journal of Agriculture and Agribusiness Socioecono-mics, 2(11). 12 hal.
Erlin R. 2017. Pemetaan sosial pela-ku utama perikanan Kecama-tan Darmaraja Kabupaten Su-medang. Laporan Tahunan. Di-nas Perikanan dan Peternakan Kabupaten Sumedang.

Indrianingsih KA. 2016. Pengaruh penyuluhan terhadap keputusan petani dalam adopsi inovasi teknologi usaha tani terpadu, Jurnal Agro Ekonomi, 29(1):1-24

Sugiyono. 2000. Metode Penelitian. Penerbit CV Alvabeta. Ban-dung. digilib.unila.ac.id

Warnaen A, Cangara A. 2016. Faktorfaktor yang menghambat ino-vasi pada komunitas petani dan nelayan dalam meningkatkan kesejahteraan masyarakat di Kabupaten Takalar. Jurnal II-mu Komunikasi, 2(3):241-250 